\title{
Leishmaniose tegumentar americana
}

\author{
American cutaneous leishmaniasis
}

Bernardo Gontijo' e Maria de Lourdes Ribeiro de Carvalho'

\begin{abstract}
Resumo A leishmaniose tegumentar americana permanence endêmica em vastas áreas da América Latina. Os agentes causadores da doença são a L. (Viannia) braziliensis, L. (L. mexicana), L. (V.) panamensis, e outras espécies relacionadas. A apresentação clínica da doença varia dentro de um espectro amplo, incluindo úlceras cutâneas múltiplas ou única, leishmaniose cutânea difusa e lesões mucosas. Os principais reservatórios da L. (V.) braziliensis e da L. (Viannia) spp. são os pequenos roedores silvestres. A doença acomete mais freqüentemente os trabalhadores que invadem as florestas tropicais ou moram próximo a elas. O período de incubação varia de duas semanas a vários meses. As lesões cutâneas constituem úlceras rasas, circulares com bordas elevadas e bem definidas e com o assoalho da úlcera de aspecto granular. Nas infecções pela L. (V.) braziliensis a linfoadenopatia regional geralmente precede o surgimento das úlcerações por uma a doze semanas. O diagnóstico definitivo depende da identificação de amastigotas em tecido ou promastigotas em meios de cultura. Os anticorpos anti-leishmania podem ser identificados no soro utilizandose as técnicas de ELISA, imunofluorescência e testes de aglutinação mas os títulos revelam-se baixos na maioria dos casos. A intradermorreação de Montenegro torna-se positiva durante a evolução da doença. Os antimoniais pentavalentes continuam sendo as drogas de escolha no tratamento da leishmaniose. A anfotericina $B$ encontra indicação nos casos mais graves ou nos indivíduos que não respondem ao tratamento com os antimoniais. A imunoterapia e a imunoprofilaxia constituem alternativas promissoras no tratamento e profilaxia da leishmaniose tegumentar americana.
\end{abstract}

Palavras-chaves: Leishmaniose. Lutzomyia sp. Glucantime. Anfotericina B.

Abstract American cutaneous leishmaniasis is endemic in widespread areas of Latin America. The causative agents include L. (V.) braziliensis, L. (L.) mexicana, L. (V.) panamensis, and related species. The spectrum of disease includes single, localized, cutaneous ulcers, diffuse cutaneous leishmaniasis, and mucosal disease. The main reservoirs for $\mathrm{L}$. (V.) braziliensis and other Leishmania (Vianna) spp. are small forest rodents. The vectors are ground-dwelling or arboreal Lutzomyia sandflies, which are abundant in the forest. Disease is most common in persons working at the edge of the forest and among rural settlers. The incubation period of cutaneous leishmaniasis varies from two weeks to several months. A wide variety of skin manifestations ranging from small, dry, crusted lesions to large, deep, mutilating ulcers may be seen. Ulcerative lesions are usually shallow and circular with well-defined, raised borders and a bed of granulation tissue. In L. (V.) braziliensis infection, regional lymphadenopathy often precedes the development of cutaneous lesions by one to 12 weeks. A definite diagnosis depends on the identification of amastigotes in tissue or promastigotes in culture. Antileishmanial antibodies are present in the serum of some patients with cutaneous leishmaniasis as detected by ELISA, immunofluorescent assays, direct agglutination tests or other assays, but the titers are usually low. The leishmanin skin test result usually becomes positive during the course of the disease. For treatment two pentavalent antimony-containing drugs are used: stibogluconate sodium, and meglumine antimoniate (Glucantime). Amphotericin B deoxycholate is an alternative for persons who fail to respond to pentavalent antimony. Immunoprophylaxis and immunotherapy are promising new approaches to prevention and treatment.

Key words: Leishmaniasis. Lutzomyia sandflies. Glucantime. Amphotericin B.

1. Faculdade de Medicina da Universidade Federal de Minas Gerais, Belo Horizonte, MG.

Endereço para correspondência: Dr. Bernardo Gontijo. Departamento de Clínica Médica/Serviço de Dermatologia/ FMUFMG, Avenida Alfredo Balena, 190, 30130-100 Belo Horizonte, MG, Brasil.

Recebido para publicação em 19/3/2002. 
As leishmanioses são doenças infecto-parasitárias que acometem o homem, causadas por várias espécies de protozoários do gênero Leishmania ${ }^{43}$. A doença pode apresentar diferentes formas clínicas, dependendo da espécie de Leishmania envolvida e da relação do parasita com seu hospedeiro ${ }^{44}$. Estes parasitas possuem a seguinte posição sistemática (após LEVINE et al, 1980)24:

Reino: PROTISTA Haeckel, 1866

Sub-reino: PROTOZOA Goldfuss, 1817

Filo: SARCOMASTIGOPHORA Honigberg \&

Balamuth, 1963

Sub-filo: MASTIGOPHORA Desing,1866

Classe: ZOOMASTIGOPHOREA Calkins, 1909

Ordem: KINETOPLASTIDA Honigberg, 1963, emend. Vickerman,1976

Sub-ordem: TRYPANOSOMATINA Kent, 1880

Família: TRYPANOSOMATIDAE Doflein,1901, emend. Grobben, 1905

Gênero: Leishmania Ross, 1903

O gênero Leishmania compreende protozoários parasitas, com um ciclo de vida digenético (heteroxênico), vivendo alternadamente em hospedeiros vertebrados e insetos vetores, estes últimos sendo responsáveis pela transmissão dos parasitas de um mamífero a outro. Nos hospedeiros mamíferos, representados na natureza por várias ordens e espécies, os parasitas assumem a forma amastigota, arredondada e imóvel, que se multiplica obrigatoriamente dentro de células do sistema monocítico fagocitário. À medida que as formas amastigotas vão se multiplicando, os macrófagos se rompem liberando parasitas que são fagocitados por outros macrófagos. Todas as espécies do gênero são transmitidas pela picada de fêmeas infectadas de dípteros da sub-família Phlebotominae, pertencentes aos gêneros Lutzomyia - no Novo Mundo, e Phlebotomus - no Velho Mundo. Nos flebotomíneos as leishmânias vivem no meio extracelular, na luz do trato digestivo. Ali, as formas amastigotas, ingeridas durante o repasto sangüíneo, se diferenciam em formas flageladas, morfológica e bioquimicamente distintas das amastigotas 19202148 , sendo posteriormente inoculadas na pele dos mamíferos durante a picada.

Com raras exceções, as leishmanioses constituem zoonoses de animais silvestres, e mais raramente domésticos, incluindo marsupiais, desdentados, carnívoros e mesmo primatas. $\mathrm{O}$ homem representa hospedeiro acidental e parece não ter um papel importante na manutenção dos parasitas na natureza. A inoculação da leishmânia determina lesão cutânea na porta de entrada, de aspecto pápulo-vesiculoso ou impetigóide, que não raro evolui para regressão espontânea. A infecção pode continuar sua marcha, surgindo lesões cutâneas disseminadas e invasão ulterior da mucosa nasofaríngea ${ }^{15}$.

\section{EPIDEMIOLOGIA}

Segundo estimativa da Organização Mundial da Saúde (OMS), a leishmaniose ocorre em 88 países e sua notificação é compulsória em apenas 30 deles. Do total de casos já registrados de leishmaniose tegumentar (LT), 90\% ocorreram em apenas seis países: Irã, Arábia Saudita, Síria e Afeganistão (Velho Mundo), Brasil e Peru, na América do Sul ${ }^{12}$.

A LTA ocorre nas Américas desde o Sul dos Estados Unidos até o norte da Argentina ${ }^{36}$. O foco mais importante é o sul-americano, que compreende todos os países, com exceção do Uruguai e do Chile.

A incidência de LTA no Brasil tem aumentado, nos últimos 20 anos, em praticamente todos os Estados. Surtos epidêmicos têm ocorrido nas regiões Sudeste,
Centro-Oeste, Nordeste e, mais recentemente, na região Amazônica, relacionados ao processo predatório de colonização ${ }^{28}$. Nos últimos anos, o Ministério da Saúde registrou média anual de 35 mil novos casos de LTA no país 6 . A Figura 1 ilustra a distribuição da LTA nos últimos anos no Brasil.

Não só no Brasil, assim como em outros países do Novo Mundo, a LTA constitui problema de Saúde Pública. Sua importância reside não somente na sua alta incidência e ampla distribuição geográfica, mas também na possibilidade de assumir formas que podem determinar lesões destrutivas, desfigurantes e também incapacitantes, com grande repercussão no campo psicossocial do indivíduo.

\section{PRINCIPAIS ESPÉCIES DE LEISHMANIA ENVOLVIDAS NA LEISHMANIOSE TEGUMENTAR AMERICANA (LTA) NO BRASIL}

Alexandre Cerqueira em 1885, na Bahia, foi o primeiro a identificar a moléstia e a suspeitar do papel dos flebotomíneos como vetores. Gaspar Vianna, em 1911, propôs a denominação de Leishmania braziliensis para o agente específico da LTA no Brasil ${ }^{47}$. Até o momento, seis espécies de Leishmania, pertencentes aos subgêneros Leishmania e Viannia, foram identificadas no Brasil como causadoras de LTA humana:
1. Leishmania (Viannia) braziliensis: é a espécie mais prevalente no homem e pode causar lesões cutâneas e mucosas. É encontrada em todas as zonas endêmicas do País, desde o norte até o sul, tanto em áreas de colonizações antigas ou recentes, estando geralmente associada à presença de animais domésticos. É transmitida por diferentes espécies de flebotomíneos como Lutzomyia whitmani, Lu. wellcomei e Lu. intermedia, dentre outras ${ }^{23}$. 


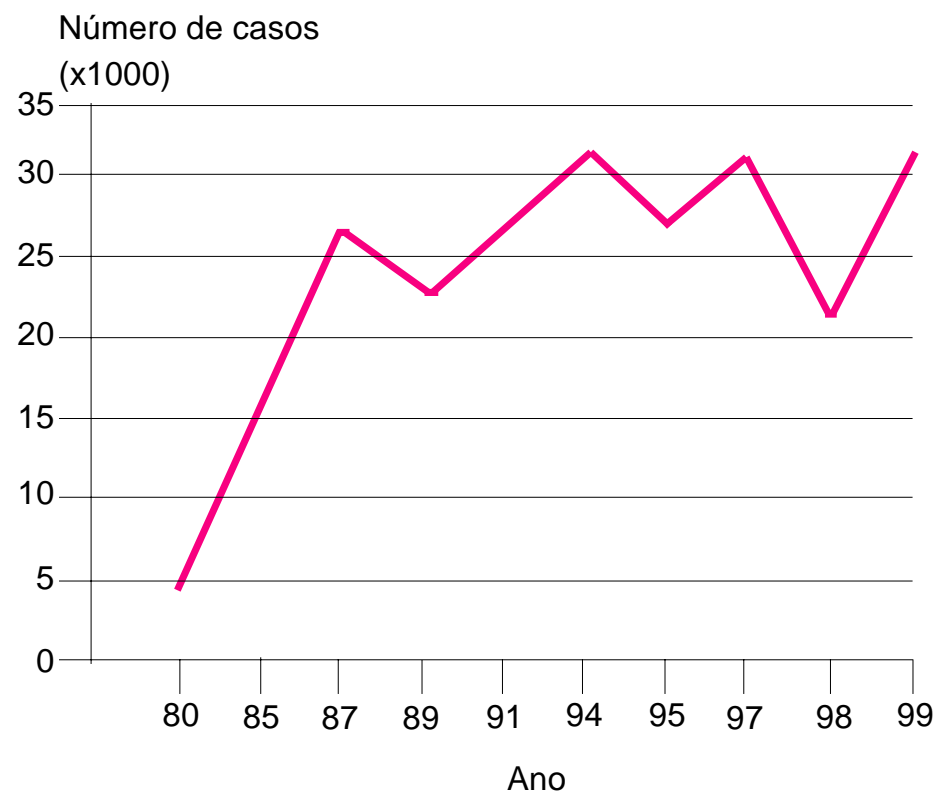

Figura 1 - Leishmaniose tegumentar americana no Brasil, no período de 1980-1999.

Fonte: Lacerda $(1994)^{22}$, FNS/Brasil $(1995)^{13}$, (CENEPI, 1999) ${ }^{6}$.

2. Leishmania (V.) guyanensis: causa sobretudo lesões cutâneas. Ocorre na margem norte do Rio Amazonas em áreas de colonização recente, estando associada com desdentados e marsupiais. As principais espécies de flebotomíneos envolvidas na transmissão são a Lu. umbratilis, Lu. anduzei e Lu. whitmani23.

3. Leishmania (V.) naiffi: ocorre na Amazônia, nos Estados do Pará e Amazonas, tendo o tatu como reservatório natural. O parasita causa LTA de evolução benigna e seus principais vetores são a Lu. squamiventris, Lu. paraensis e Lu. Ayrozałt5.
4. Leishmania (V.) shawi: responsável por casos esporádicos no Amazonas e Pará, tem como reservatórios vários animais silvestres como macacos, preguiças e procionídeos e como vetor a Lu. whitmanit ${ }^{46}$.

5. Leishmania (V.) lainsoni: registrada apenas na Amazônia, tem a paca como animal suspeito de reservatório natural e como vetor a $L u$. ubiquitalis ${ }^{46}$.

6. Leishmania (Leishmania) amazonensis: agente etiológico de LTA, incluindo a forma anérgica ou leishmaniose cutânea difusa. Seus reservatórios são roedores e marsupiais e a Lu. flaviscutellata e Lu. olmeca os principais vetores ${ }^{46}$.

\section{DIAGNÓSTICO DA LEISHMANIOSE TEGUMENTAR AMERICANA (LTA)}

O diagnóstico de LTA abrange aspectos epidemiológicos, clínicos e laboratoriais (pesquisa parasitológica e diagnóstico imunológico). Freqüentemente a associação de alguns desses elementos é necessária para se chegar ao diagnóstico final26.

Diagnóstico Clínico: o diagnóstico clínico da LTA pode ser feito com base nas características da lesão associadas à anamnese, onde os dados epidemiológicos são de grande importância. As formas tegumentares do Novo Mundo compreendem uma síndrome cujas manifestações clínicas dependem de alguns fatores, como a espécie de Leishmania envolvida e a relação do parasita com seu hospedeiro ${ }^{44}$. A LTA produz um amplo espectro de lesões, o que torna o diagnóstico clínico nem sempre simples ou imediato.

A leishmaniose cutânea (LC) é definida pela presença de lesões exclusivamente na pele, que se iniciam no ponto de inoculação das promastigotas infectantes, através da picada do vetor, para qualquer das espécies de Leishmania causadoras da doença. A lesão primária é geralmente única, embora eventualmente múltiplas picadas do flebotomíneo ou a disseminação local possam gerar um número elevado de lesões ${ }^{28}$. Surge após um período de incubação variável de 10 dias a três meses, como uma pápula eritematosa que progride lentamente para nódulo. Acompanha-se de adenopatia regional, com ou sem linfangite, em 12 a 30\% dos casos. Com a evolução, ganha destaque o notável polimorfismo das lesões sendo possível encontrar formas impetigóide, liquenóide, tuberculosa ou lupóide, nodular, vegetante e ectimatóide. São freqüentes as ulcerações com bordas elevadas, enduradas e fundo com tecido de granulação 
PACIENTE

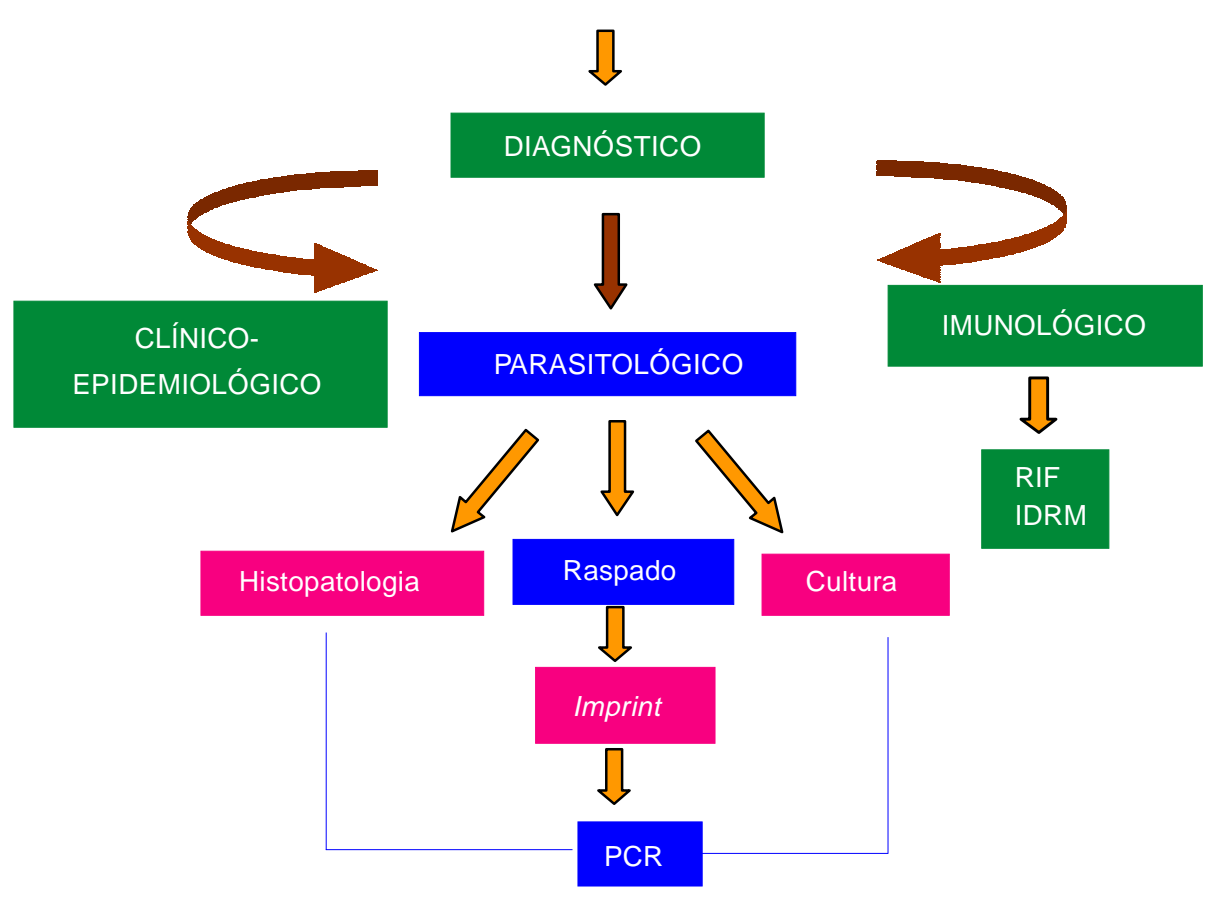

grosseira, configurando a clássica lesão com borda em moldura (Figura 2-A). O quadro é normalmente assintomático, predominando nas áreas corpóreas descobertas e se instala em pacientes de áreas endêmicas ou que lá estiveram recentemente. Pode ter decurso abortivo ou assumir caráter tórpido, para terminar em regressão espontânea, conforme observado em vários focos brasileiros. Na maioria dos casos, a infecção progride e, após um período de latência clínica de vários meses de duração, surgem as lesões cutâneas e/ou mucosas, conseqüentes à disseminação hematogênica e/ou linfática do parasita ${ }^{15}$.

A leishmaniose mucosa (LM) (Figura 2-B), também denominada espúndia, é condição de difícil tratamento e prognóstico reservado quanto à possibilidade de cura. Está associada à L. braziliensis, na maioria dos casos ocorrendo em um intervalo de tempo variável após a instalação da lesão cutânea inicial. Os fatores que contribuem para que uma doença inicialmente cutânea evolua para essa forma tardia não são de todo conhecidos, mas sabe-se que a demora na cicatrização da lesão primária e tratamento inicial inadequado podem estar associados ${ }^{27} 384$. O acometimento mucoso pode surgir com a lesão cutânea ainda em atividade, ou anos após sua cicatrização. Dentre as lesões mucosas distinguem-se as seguintes variedades: forma úlcero-infiltrante, poliposa e terebrante. $\mathrm{Na}$ quase totalidade dos casos a LM acomete a mucosa nasal, com importante comprometimento do septo, seguindose em ordem de freqüência o envolvimento da mucosa oral. Em ambos os casos o risco de deformidades permanentes é considerável ${ }^{17} 40$. O acometimento de outras mucosas que não as das vias aéreas superiores é excepcional ${ }^{27}$.

O comprometimento ósseo é raro, ocorrendo geralmente por contigüidade com lesões cutâneas ${ }^{42}$.

Entre as formas menos comuns de LTA encontrase a leishmaniose cutânea difusa (LCD) (Figura 2-C) situada no pólo anérgico da doença, em oposição à forma polar resistente representada pela leishmaniose cutânea-mucosa (LCM) e parte das leishmanioses cutâneas localizadas $(\mathrm{LCL})^{9}$. Suas lesões nodulares e infiltrações cutâneas pronunciadas simulam quadro de hanseníase virchowiana ${ }^{40}{ }^{17}$. As lesões, via de regra, não cicatrizam espontaneamente e são classicamente rebeldes ao tratamento medicamentoso ${ }^{8} 3811$. O diagnóstico diferencial é feito com a forma cutânea disseminada (Figura 2-D) que é caracterizada por lesões múltiplas, geralmente ulceradas, distribuídas por diversas áreas do tegumento, distantes do sítio de inoculação primária ${ }^{29}$. As lesões podem ser muito numerosas ${ }^{10} 3$, mas respondem ao tratamento medicamentoso habitual. A forma disseminada usualmente apresenta a imunidade celular preservada, evidenciada pela positividade da intradermorreação de Montenegro. 


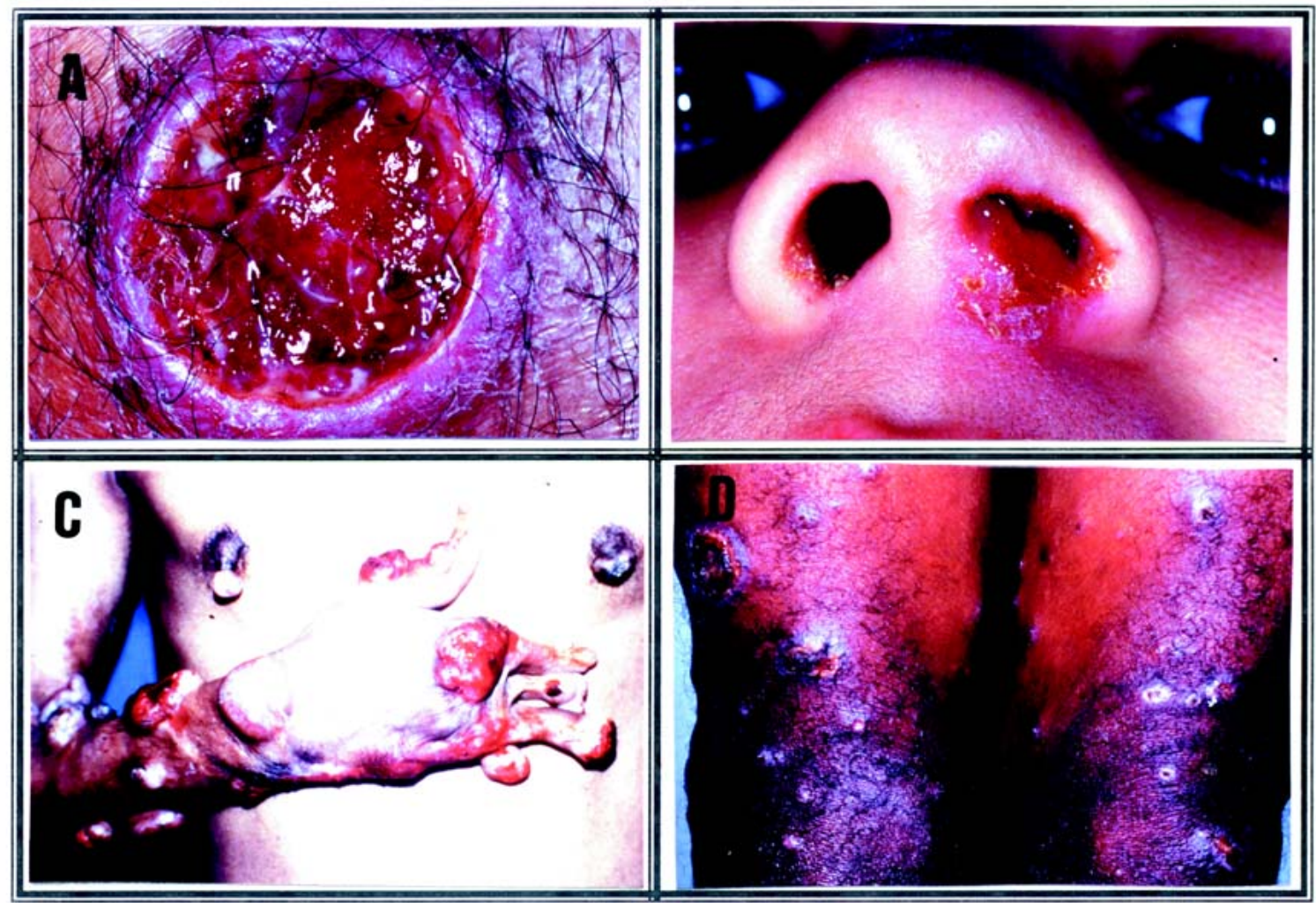

Figura 2- LTA. (A) Forma cutânea (lesão clássica em moldura); (B) Forma mucosa; (C) Forma difusa; (D) Forma disseminada.

Há ainda uma forma de leishmaniose que se manifesta com o aumento dos nódulos linfáticos, sem a concomitância de lesões cutâneas e/ou mucosas ${ }^{341}$.

Diagnóstico Diferencial: As formas cutâneas devem ser diferenciadas das úlceras traumáticas, úlceras de estase, úlcera tropical, úlceras de membros inferiores por anemia falciforme, piodermites, paracoccidioidomicose, neoplasias cutâneas, sífilis e tuberculose cutânea. A hanseníase virchowiana deverá ser excluída, principalmente no diagnóstico diferencial da leishmaniose cutânea difusa. Nas lesões mucosas, o diagnóstico diferencial deve ser feito com a paracoccidioidomicose, hanseníase virchowiana, rinoscleroma, bouba, sífilis terciária, granuloma médio facial e neoplasias ${ }^{36}$. Nas formas vegetantes, distingue-se a variedade verrucosa, muito freqüente, que simula a esporotricose verrucosa, a cromomicose, a paracoccidioidomicose, a piodermite vegetante e a tuberculose verrucosa ${ }^{15}$. (Figura 3 e 4).

Diagnóstico Parasitológico: o diagnóstico de certeza somente se obtém pela demonstração do parasita, que pode ser conseguida através de diferentes técnicas parasitológicas de pesquisa direta e indireta. $\mathrm{O}$ exame mais simples, e por essa razão geralmente o primeiro a ser realizado, é a pesquisa direta das formas amastigotas em material obtido da lesão por escarificação, aspiração ou biópsia da borda, corado pelo Giemsa ou Leishman (Figura 5).

A chance de se encontrar o parasita é inversamente proporcional ao tempo de duração da lesão e a sensibilidade do método nos casos produzidos por $L$. braziliensis está em torno de $100 \%$ nos dois primeiros meses de evolução, $75 \%$ aos seis meses e $20 \%$ acima dos 12 meses $^{14}$.

O parasita cresce relativamente bem em diversos meios de cultura à temperatura ambiente $\left(24-26^{\circ} \mathrm{C}\right) . \mathrm{O}$ meio mais empregado para isolamento é o ágar-sangue de Novy e McNeal modificado por Nicolle-NNN, e suas modificações ${ }^{30}$. A sensibilidade global do método está em torno de $50 \%$ para L. braziliensis ${ }^{35}$. Esse procedimento, contudo, exige facilidades laboratoriais e pessoal treinado, muitas vezes não disponível em nosso país, o que o torna inadequado para inquérito epidemiológico de larga escala.

Outra forma de diagnóstico parasitológico é a inoculação em animais de laboratório, de preferência hamster (Mesocricetus auratus), nas patas posteriores ou focinho. Além do longo tempo necessário para a evolução da lesão no modelo animal (2 a 9 meses, em média), a eficácia do isolamento apresenta grande variação conforme a espécie de Leishmania ${ }^{36}$. 


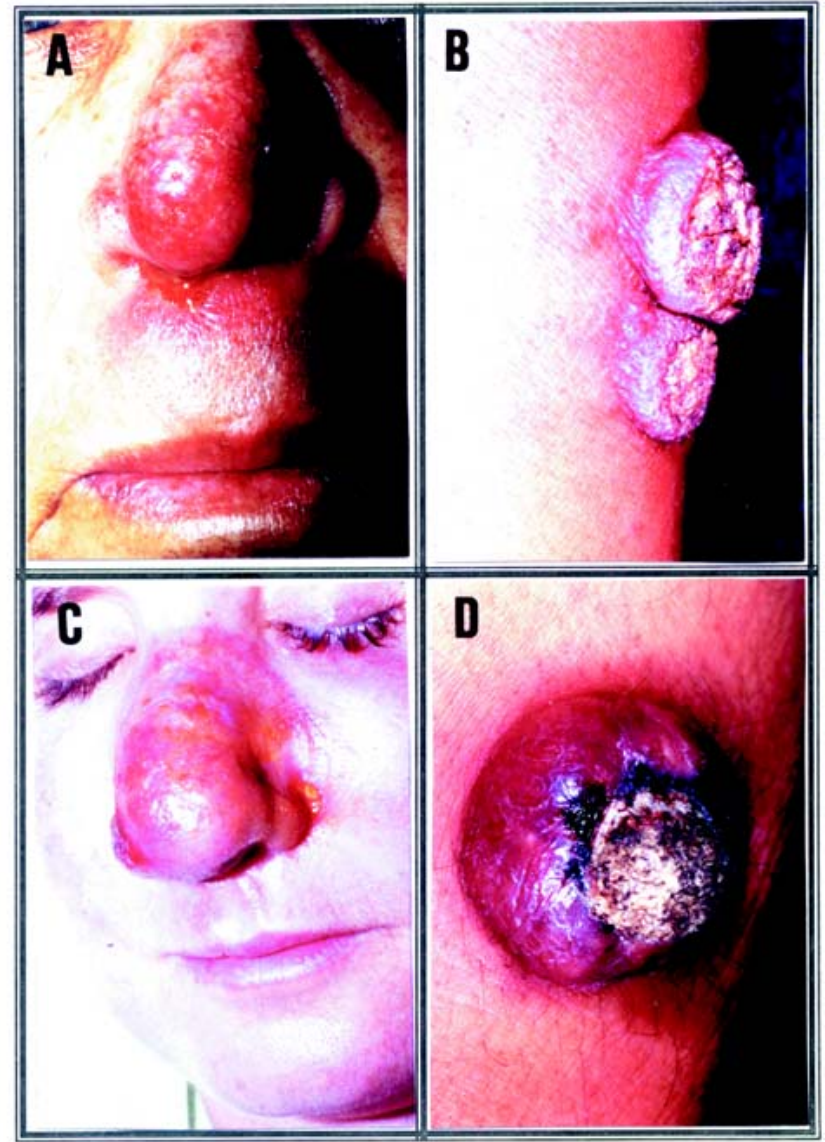

Figura 3- (A) - LTA (infiltracão nasal); (B) - LTA (forma vegetante); (C) e (D) - Diagnóstico diferencial da LTA (granulomatose de Wegener e ceratoacantoma, respectivamente).

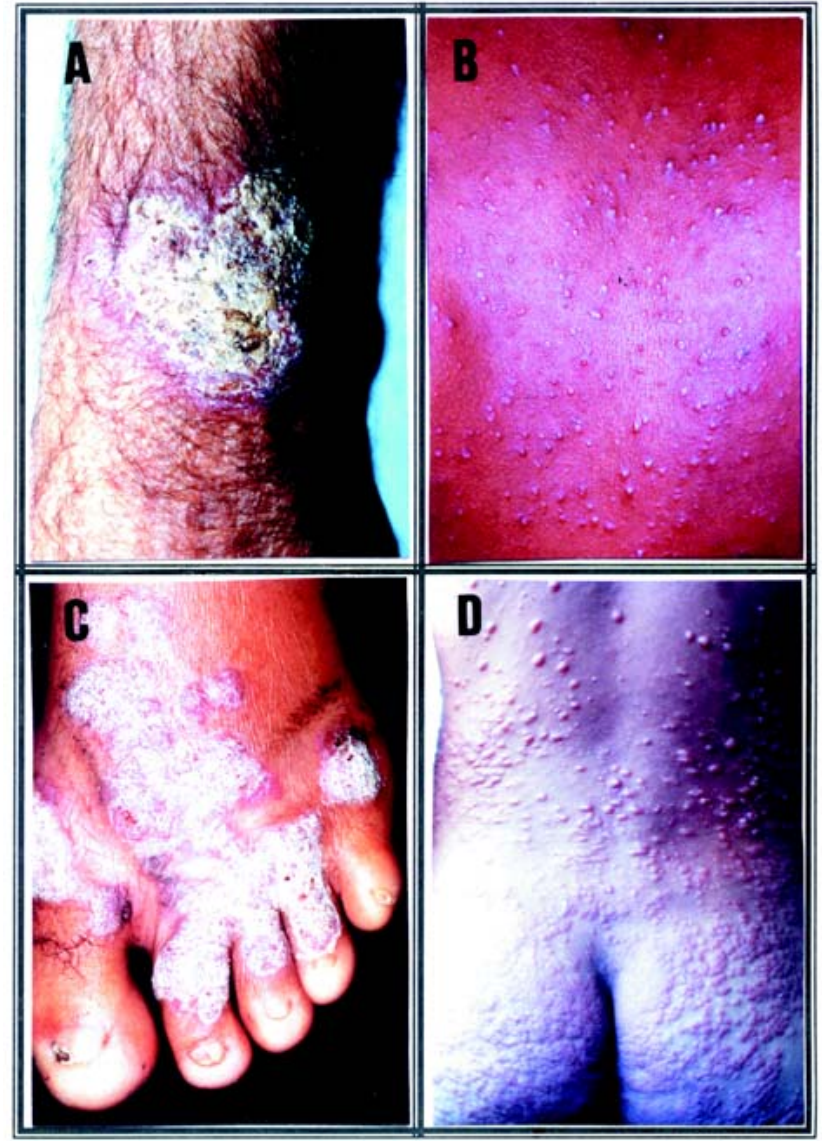

Figura 4 - LTA (forma hiperceratósica): (B) LTA (forma difusa); (C) e (D)- Diagnóstico diferencial da LTA (cromomicose e sífilis secundaria, respectivamente).

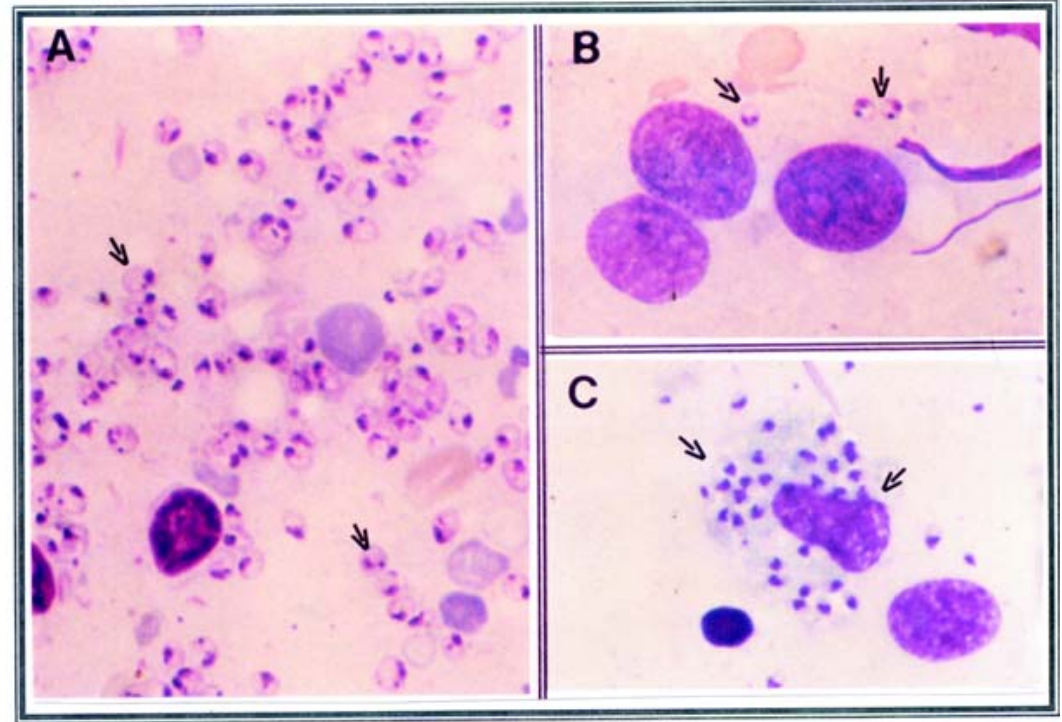

Figura 5- Esfregaço por aposição de material biopsiado de leșão de pacientes de LTA, corados pelo Giemsa. (A) Leishmania do complexo mexicana (1000X); (B) Leishmania do complexo braziliensis (1000X); (C) Macrófago parasitado com amastigotas (1000X). 
Em relação à pesquisa de parasitas em cortes histológicos, a análise comparativa das alterações histopatológicas de quatro grupos geograficamente distintos de leishmaniose cutânea, em um total de 147 pacientes, evidenciou os seguintes resultados. No grupo brasileiro, onde a pesquisa do parasita nos cortes histológicos foi quase sempre negativa, a agressão máxima ocorreu no tecido conjuntivo. No grupo da América Central, onde as formas amastigotas foram detectadas em pequeno número de casos, o dano ao tecido conjuntivo foi moderado e aparentemente associado à lise dos macrófagos parasitados e liberação de parasita para o meio extracelular. Em dois grupos do Velho Mundo, ambos com encontro de numerosos parasitas, a necrose dos macrófagos não ocorreu de forma isolada, mas sim como uma massa localizada, não havendo dispersão extracelular da Leishmania. 0 dano tissular, com raras exceções, foi mínimo ${ }^{41}$.

Em um extenso e clássico estudo de LTA no Brasil, analisaram-se biópsias de 378 pacientes infectados com L. braziliensis que, através das alterações dérmicas ou do córion da mucosa, permitiram identificar a existência de cinco padrões histopatológicos: 1-reação exsudativa celular; 2-reação exsudativa e necrótica; 3-reação exsudativa e necrótica-granulomatosa; 4-reação exsudativa e granulomatosa e 5-reação exsudativa e tuberculóide. Os parasitas, embora escassos, foram encontrados em $63,7 \%$ dos casos de forma cutânea e em $37,5 \%$ dos casos de forma mucosa. Através desse estudo, foi possível afirmar que o padrão de reação exsudativa celular constitui o quadro inicial e final da lesão, com os demais padrões aparecendo interpostos durante a evolução da doença ${ }^{25}$. É importante destacar que o diagnóstico histopatológico de certeza da LTA só é possível mediante o achado dos parasitas. Caso contrário, as alterações histopatológicas são, no máximo, sugestivas do diagnóstico.

A reação em cadeia da polimerase (polymerase chain reaction)-PCR é um exame que permite amplificar em escala exponencial seqüências de DNA. Dotada de alta sensibilidade, é capaz de detectar quantidades tão pequenas quanto 1 fentograma ( 1 fentograma $=10^{-15} \mathrm{~g}$ ) do DNA de uma leishmânia, o equivalente a 1/10 do parasita ${ }^{2}$. Entretanto, as exigências técnicas e o custo relativamente elevado ainda limitam seu emprego rotineiro. Em nosso meio foi determinada uma sensibilidade de $98,41 \%$ e especificidade de $95,59 \%$ no diagnóstico da $\mathrm{LTA}^{16}$.

\section{DIAGNÓSTICO IMUNOLÓGICO}

Intradermorreação de Montenegro (IDRM): Em 1926, Montenegro realizou pela primeira vez a reação intradérmica com antígeno preparado de formas de cultura de Leishmania sp para diagnóstico da moléstia, teste este ainda hoje amplamente empregado e bastante útil ${ }^{33}{ }^{37}$. A IDRM detecta a presença de hipersensibilidade tardia uma vez que, imunologicamente, a LTA se caracteriza pelo aparecimento de uma resposta celular durante a doença e após a cura da infecção, seja de forma espontânea ou após tratamento ${ }^{4}$. A técnica consiste na injeção na face flexora do antebraço de $0,1 \mathrm{ml}$ de antígeno padronizado com a concentração de $40 \mathrm{mg}$ de nitrogênio protéico por $\mathrm{ml}^{30}$. A reação é considerada positiva quando, na leitura de 48 ou 72 horas, detecta-se enduração igual ou superior a $5 \mathrm{~mm}$. O teste se torna positivo em torno de quatro meses após o início da lesão cutânea, mas não diferencia doença atual e pregressa (na maioria das vezes permanece positivo após o tratamento), nem distingue doença de infecção, e é habitualmente negativo nas formas cutâneas difusas e nos pacientes imunodeprimidos ${ }^{36}$. A IDRM é de grande valor presuntivo no diagnóstico de LTA, constituindo valioso recurso diagnóstico nos casos em que os parasitas são escassos ou ausentes, sendo também bastante útil nos inquéritos epidemiológicos de áreas endêmicas. Estima-se uma positividade de $84 \%$ e $100 \%$ nas formas cutâneas e mucocutânea, respectivamente, e resultados negativos na forma cutânea difusa ${ }^{46}$.

Reações sorológicas: Dentre os métodos sorológicos, a reação de imunofluorescência indireta (RIFI) é o mais utilizado. É uma técnica sensível, porém com possibilidade de reações cruzadas especialmente com a doença de Chagas e calazar ${ }^{18}$. A RIFI apresenta resultados variáveis na LTA, quer pela reduzida antigenicidade do parasita ou pelos baixos níveis de anticorpos circulantes. Habitualmente negativa na forma cutânea difusa, sua sensibilidade foi estimada em $71 \%$ nas formas cutâneas e $100 \%$ na forma mucosa ${ }^{32}$. Em pacientes com lesões recentes (um a seis meses de evolução), é freqüente a negatividade sorológica. Nos casos positivos, os títulos médios são significativamente mais elevados naqueles que apresentam múltiplas lesões, refletindo a maior antigenicidade induzida pelo maior número de parasitas. Além disso, o número de reações sorológicas negativas é maior entre os que possuem o exame parasitológico positivo quando comparado àqueles em que a pesquisa direta do parasita revela-se negativa ${ }^{7}$. Após o tratamento e cura, os títulos podem cair ou desaparecer em alguns meses ${ }^{536}$.

\section{TRATAMENTO}

A droga de primeira escolha é o antimonial pentavalente, existente sob duas formas: o antimoniato de $N$-metilglucamina e o stibogluconato de sódio, sendo que este último não é comercializado no Brasil. Visando padronizar o esquema terapêutico, a Organização
Mundial da Saúde (OMS) recomenda que a dose do antimonial seja calculada em $\mathrm{mg} / \mathrm{Sb} / \mathrm{Kg} / \mathrm{dia} .\left(\mathrm{Sb}^{\vee}=\right.$ antimônio pentavalente). O antimoniato de $\mathrm{N}$ metilglucamina é comercializado em frasco de $5 \mathrm{ml}$ que contém $1,5 \mathrm{~g}$ do antimoniato bruto, correspondente a 
$425 \mathrm{mg}$ de $\mathrm{Sb}^{\vee}$. Portanto, cada $\mathrm{ml}$ contém $85 \mathrm{mg}$ de $\mathrm{Sb}^{\vee}$. Este antimonial é indicado para tratamento de todas as formas de leishmaniose tegumentar, embora as formas mucosas exijam maior cuidado, podendo apresentar respostas mais lentas e maior possibilidade de recidivas ${ }^{36}$. As lesões ulceradas podem sofrer contaminação secundária, razão pela qual devem ser prescritos cuidados locais. São as seguintes as recomendações do Ministério da Saúde/Fundação Nacional da Saúde ${ }^{36}$ para o uso do antimoniato de $N$-metilglucamina:

a) nas formas cutâneas localizadas e disseminadas a dose varia entre 10 a $20 \mathrm{mg} / \mathrm{Sb} / \mathrm{Kg} / \mathrm{dia}$. Sugere-se $15 \mathrm{mg} / \mathrm{Sb}^{\mathrm{V}} / \mathrm{Kg} /$ dia tanto para adultos quanto para crianças, durante 20 dias seguidos, aplicados IM ou EV. A dose diária não deve ultrapassar $15 \mathrm{ml}$ (três ampolas). Se não houver cicatrização completa três meses (12 semanas) após o término do tratamento, o esquema deverá ser repetido, prolongando-se, desta vez, a duração da série para 30 dias. Persistindo o insucesso terapêutico, deve ser utilizada uma das drogas de segunda escolha. Na forma difusa a dose é de $20 \mathrm{mg} /$ $\mathrm{Sb}^{\mathrm{V}} / \mathrm{Kg} /$ dia, durante 20 dias seguidos. Inicialmente podese observar relativa resposta terapêutica, porém são freqüentes as múltiplas recidivas.

b) em todas as formas de acometimento mucoso a dose recomendada é de $20 \mathrm{mg} / \mathrm{Sb} / \mathrm{Kg} / \mathrm{dia}$, durante 30 dias consecutivos, preferencialmente em ambiente hospitalar. Se não houver cicatrização completa três meses (12 semanas) após o término do tratamento, o esquema deverá ser repetido apenas uma vez. Pacientes não responsivos devem utilizar uma das drogas de segunda escolha.

Os efeitos colaterais mais freqüentes são artralgia, mialgia, inapetência, cefaléia, febre, vômitos, tontura e inchaço no local da aplicação. A cardio, nefro e hepatoxicidade dos antimoniais constituem uma importante limitação à sua segurança. Idealmente os pacientes, em especial os mais idosos, devem ser submetidos à avaliação cardiológica prévia. Por serem abortivos, os antimoniais não podem ser administrados a gestantes.

A Anfotericina $B$, antibiótico poliênico de reconhecida ação leishmanicida, é a droga de segunda escolha, empregada quando não se obtém resposta ao tratamento com antimonial ou na impossibilidade de seu uso. Considerada mais eficaz que os antimoniais no tratamento das lesões mucosas, é apresentada em frascos de $50 \mathrm{mg}$ (Fungizonâ) para uso EV. A dose inicial de $0,5 \mathrm{mg} / \mathrm{kg} /$ dia deve ser aumentada gradativamente, conforme a tolerância do paciente, até $1 \mathrm{mg} / \mathrm{kg} / \mathrm{dia}$. A administração deve ser feita em dias alternados, respeitando-se o limite máximo de 50mg (1 frasco) por aplicação, até a dose total de 1 a $1,5 \mathrm{~g}$ para $L C$ e de 2,5 a $3 \mathrm{~g}$ para $L M$ ou LCM. O antibiótico deve ser diluído em soro glicosado (o soro fisiológico provoca inativação da droga) e infundido gota a gota. Para prevenção dos episódios de flebite podem ser acrescentados $100 \mathrm{mg}$ de hidrocortisona. Os efeitos colaterais mais comuns incluem náuseas, vômitos, febre, hipopotassemia, insuficiência renal, anemia e alterações cardíacas. A cardio e nefrotoxicidade, além do uso EV, impedem seu uso fora do ambiente hospitalar.

Poucos estudos foram realizados nas Américas utilizando as pentamidinas na terapêutica da LTA. A dose preconizada é de $4 \mathrm{mg} / \mathrm{kg} / \mathrm{dia}$, por via intramuscular profunda, de 2 em 2 dias, recomendando-se não ultrapassar a dose total de $2 \mathrm{~g}^{36}$.

\section{CRITÉRIOS DE CURA}

O critério de cura é clínico. Recomenda-se acompanhamento mensal por três meses consecutivos e, após a cura clínica, seguimento até 12 meses após o término do tratamento. Na forma cutânea o critério de cura é definido pelo aspecto clínico das lesões: reepitelização das lesões ulceradas ou não-ulceradas, regressão total da infiltração e eritema, até três meses após a conclusão do esquema terapêutico. E na forma mucosa é definido pela regressão de todos os sinais e comprovado pelo exame otorrinolaringológico, até seis meses após a conclusão do esquema terapêutico ${ }^{36}$.

\section{PROFILAXIA}

Conhecer a população afetada pela LTA em nosso País é de fundamental importância para o estabelecimento de medidas eficazes de controle da doença. As diferenças na morbidade, resposta ao tratamento e prognóstico, relacionadas em parte à espécie de Leishmania, evidenciam a importância da caracterização do parasita prevalente em determinada região.
No seu conjunto, estes estudos são muito importantes para se compreender a eco-epidemiologia da doença, diagnosticá-la, tratá-la, determinar os mecanismos envolvidos e assim definir estratégias e medidas eficientes de profilaxia e controle. A imunoterapia e a imunoprofilaxia, embora com resultados ainda preliminares, representam possibilidade futura promissora.

\section{REFERÊNCIAS BIBLIOGRÁFICAS}

1. Barral-Netto M, Barral A, Brodskyn C, Carvalho EM, Reed SG. Cytotoxicity in human mucosal and cutaneous leishmaniasis. Parasite Immunology 17: 21-28, 1995.
2. Brujin MHL, Barker DC. Diagnosis of New World Leishmaniasis: specific detection of species of the L. braziliensis complex by amplification of kinetoplast DNA. Acta Tropica 52: 45-58, 1992. 
3. Carvalho EM, Barral A, Costa JML, Bittencourt A, Marsden PD Clinical and immunopathological aspects of disseminated cutaneous leishmaniasis. Acta Tropica 56: 315-325, 1994.

4. Carvalho EM, Correa-Filho D, Barcelar O, Almeida RP, Less $\mathrm{H}$, Rocha $\mathrm{H}$. Characterization of the immune response in subjects with self-healing cutaneous leishmaniasis. American Journal of Tropical Medicine and Hygiene 53: 273-277, 1995.

5. Carvalho MLR. Aspectos da imunidade celular em pacientes com leishmaniose tegumentar americana, procedentes de área endêmica do Estado de Mato Grosso-Brasil, antes e após o tratamento com antimonial pentavalente. (Tese de Doutoramento) Instituto de Ciências Biológicas-Universidade Federal de Minas Gerais-Brasil ), p.157, 2000.

6. CENEPI/ Ministério da Saúde - (Notas de dados estatísticos), 1999.

7. Chiari AC, Mayrink W, Magalhães PA. Reação de imunofluorescência no controle do tratamento da leishmaniose tegumentar americana. Revista do Instituto de Medicina Tropical de São Paulo 15: 298-303, 1973.

8. Convit J, Kerdel-Vegas F. Disseminated cutaneous leishmaniasis. Archives of Dermatology 91: 439-447, 1965.

9. Convit J, Ulrich M, Fernandez CT, Tapia FJ, Cáceres-Ditmar G, Cástes M, Rondón AJ. The clinical and immunological spectrum of American cutaneous leishmaniasis. Transactions of the Royal Society of Tropical Medicine and Hygiene 87: 444-448, 1993.

10. Costa JML, Marsden PD, Llanos-Cuentas EA, Neto EM, Carvalho EM, Barral A, Rosa AC, Cuba CC, Magalhães AV, Barreto AC. Disseminated cutaneous leishmaniasis in a field clinic in Bahia, Brazil: a report on eight cases. Journal of Tropical Medicine and Hygiene 89: 318-323, 1986.

11. Costa JML, Saldanha ACR, Silva ACM, Serra-Neto A, Galvão CES, Silva CMP, Silva AR. Estado atual da leishmaniose cutânea difusa (LCD) no Estado do Maranhão. II. Aspectos epidemiológicos e clínico-evolutivos. Revista da Sociedade Brasileira de Medicina Tropical 25: 115-123, 1992.

12. Desjeux P. Aspects de Santé publique et lutte. In: DEDET, J. P. Les Leishmanioses. Paris: AUPELF-UREFF-Ellipses, p.219-238, 1999.

13. Fundação Nacional de Saúde, 1995 (Notas de dados estatísticos).

14. Furtado T. Critérios para diagnóstico de LTA. Anais Brasileiros de Dermatologia 65: 51-86, 1980.

15. Furtado T. Leishmaniose Tegumentar Americana. In: MachadoPinto J(ed), Doenças infecciosas com manifestações dermatológicas. Editora Médica e Científica Ltda, Rio de Janeiro, p.319-328, 1994

16. Gontijo BA. Reação em Cadeia da Polimerase (PCR) no Diagnóstico da Leishmaniose Tegumentar Americana.(Tese de Doutoramento) Faculdade de Medicina-Universidade Federal de Minas Gerais - Brasil, 91p, 1997.

17. Grevelink SA, Lerner E. Leishmaniasis. Journal of the American Academy of Dermatology 34: 2 (Part 1), 257-272, 1996.

18. Kar K. Serodiagnosis of leishmaniasis. Critical Review of Microbiology 21: 123-152,1995.

19. Killick-Kendrick R. The biology of Leishmania in phlebotomine sandflies. In: Biology of Kinetoplastida, vol.II (eds W.H.R.
Lumsden \& D. A. Evans) Academic Press, London/New York, 395-460, 1979.

20. Killick-Kendrick R. The life-cycle of Leishmania in the sandfly with special references to the form infective to the vertebrate host. Annales de Parasitologie Humaine et Compareé 65 (suppl. 1): 37-42, 1990

21. Killick-Kendrick R, Rioux JA. Intravectorial cycle of Leishmania in the sandflies. Annales de Parasitologie Humaine et Compareé 66 (suppl. 1): 71-74, 1991.

22. Lacerda MM. The Brazilian leishmaniasis control program. Memórias do Instituto Oswaldo Cruz 89: 489-495, 1994.

23. Lainson R, Shaw JJ. Evolution, classification and geographical distribution. In: The leishmaniasis. London, Peters W. \& KillickKendrick R. v.1, p.1-128,1987.

24. Levine ND, Corliss JO, Cox FEG, Deroux G, Grain J, Ronigberg BM, Lieedale GF, Leoeblich AR, Lom J, Lynn D, Merinfeld EG, Page FC, Poljansky G, Sprague V, Vávra J, Wallace FG. A newly revised classification of the PROTOZOA. Journal of Protozoology 27: 37-58, 1980

25. Magalhães AV, Moraes MAP, Raick AN, Llanos-Cuentas EA, Costa JML, Cuba CC, Marsden PD. Histopatologia da leishmaniose tegumentar por Leishmania b. braziliensis. Padrões histológicos e estudo evolutivo das lesões. Revista do Instituto de Medicina Tropical de São Paulo, 28: 253-262, 1986.

26. Manson-Bahr PE. Diagnosis. In: The Leishmaniasis. London, Peters W. \& Kilich-Kendrick R, v.2, p.703-728, 1987.

27. Marsden PD. Mucosal leishmaniasis (Espundia Escomel,1911). Transactions of the Royal Society of Tropical Medicine and Hygiene 80: 859-876, 1986.

28. Marzochi MC. A Leishmanioses no Brasil: as leishmanioses tegumentares. Journal Brasileiro de Medicina 63: 82-104, 1992.

29. Marzochi MC, Marzochi KBF. Tegumentary and visceral leishmaniasis in Brazil: emerging anthropozoonosis and for their control. Cadernos de Saúde Pública 10(supl. 2): 359-375, 1994.

30. Melo MN. Cultivo de Leishmania em meio definido. Estudo de seus requerimentos nutricionais..(Tese de Doutoramento), Instituto de Ciências Biológicas da Universidade Federal de Minas Gerais - Brasil, 133p,1982.

31. Melo MN, Mayrik W, Costa CA, Magalhães PA, Williams P, Araújo FG, Coelho MV, Batista SM. Padronização do antígeno de Montenegro. Revista do Instituto de Medicina Tropical de São Paulo 19: 161-164,1977.

32. Mendonca SCF, Sousa WJS, Nunes MP, Marzochi MCA, Coutinho SG. Indirect immunofluorescence test in New World leishmaniasis: serological and clinical relationship. Memórias do Instituto Oswaldo Cruz., 83: 347-355, 1988.

33. Ministério da Saúde /FNS, Guia de controle de LTABrasília,1994.

34. Ministério da Saúde /FUNASA, Guia de controle de LTABrasília,2000.

35. Montenegro J. A cutis-reação na leishmaniose. In: Anais da Faculdade de Medicina de São Paulo 1:323-330, 1926.

36. Montenegro J. Cutaneous reactions in leishmaniasis. Archives of Dermatology and Syphilology 13:187,1926.

37. Morais MAP, Correa Filho D, Santos JB. Linfoadenopatias na Leishmaniose Tegumentar Americana: considerações sobre dois 
casos. Revista da Sociedade Brasileira de Medicina Tropical 26:181-185, 1993

38. Organizacion Mundial de la Salud - Lucha contra las leishmaniasis. Ginebra, OMS, 178p. (Série de Informes Técnicos, 793) 1990.

39. Organizacion Panamericana de la Salud. La leishmaniasis en las Américas, OPAS, v.1, p.8-13. (Boletin Epidemiológico, 15), 1994.

40. Pearson RD, Sousa AQ. Clinical spectrum of leishmaniasis. Clinical Infectious Diseases, 22: 1-13, 1996.

41. Ridley DS. A histological classification of cutaneous leishmaniasis and its geographical expression. Transactions of the Royal Society of Tropical Medicine and Hygiene 74:515-521, 1980.

42. Rodriguez LV, Uzquiano FC, Desjeux P, Valle SWC. Leishmaniose recidivante com alterações ósseas-relato de caso. Anais Brasileiros de Dermatologia 63:31-34, 1988.

43. Ross R. Further Notes on Leishmania's bodies. British Medical Journal 11:1401, 1903.
44. Saravia NGL Valderrama M, Labrada AF, Holguín C, Navas G, Palma A, Weigle KA. The relationship of Leishmania braziliensis subspecies and immune response to disease expression in New World leishmaniasis. Journal of Infectious Diseases 159:725-735, 1989.

45. Shaw JJ. The relatonship of sand fly ecology to the transmission of leishmaniasis in South America with particular reference to Brasil. In: Memoirs on Entomology, International. JFB.(eds). Associated Publishers, 1999.

46. Shaw JJ, Lainson R. Leishmaniasis in Brazil: Some observations on intradermal reactions to different trypanosomatid antigens of patients suffering from cutaneous and mucocutaneous leishmaniosis. Transactions of the Royal Society of Tropical Medicine and Hygiene 69:323-335, 1975

47. Viannia G. Sobre uma espécie de Leishmania. Brasil Médico 25:411, 1912.

48. Walters LL. Leishmania differentiation in natural and unnatural sandfly host. Journal of Eukaryotic Microbiology 40: 1990. 196-206, 1993. 